\title{
Language mixing within verbs and nouns in American Norwegian
}

Authors:

1. Brita Ramsevik Riksem

Norwegian University of Science and Technology, Dragvoll, Edvard Bulls veg 1, 7048 Trondheim, Norway

\section{Maren Berg Grimstad}

Norwegian University of Science and Technology, Dragvoll, Edvard Bulls veg 1, 7048 Trondheim, Norway

\section{Terje Lohndal}

Norwegian University of Science and Technology, Dragvoll, Edvard Bulls veg 1, 7048 Trondheim, Norway \& UiT The Arctic University of Norway

\section{Tor A. Åfarli}

Norwegian University of Science and Technology, Dragvoll, Edvard Bulls veg 1, 7048 Trondheim, Norway

Corresponding author:

Tor A. Åfarli: $\quad$ tor.aafarli@ntnu.no

\begin{abstract}
This paper presents case-studies of language mixing within verbs and nouns in the heritage language American Norwegian, which refers to varieties spoken by Norwegian immigrants to the US and their descendants. The paper builds on data from the newly established Corpus of American Norwegian Speech and argues in favor of an exoskeletal approach to language mixing. This approach distinguishes between abstract syntactic feature bundles and the morphophonological realization of these bundles, much like in late insertion approaches to morphology. A main goal of the paper is to show how the word-internal mixing patterns observed in American Norwegian can be analyzed in a model of grammar employing an exoskeletal approach with a late-insertion approach to morphology.
\end{abstract}

\section{Keywords}

American Norwegian, Exoskeletal, Language mixing, Late Insertion, Word-internal language mixing 


\section{Introduction}

This paper will focus on language mixing in the heritage language American Norwegian. This is the variety of Norwegian used by speakers who immigrated to the US during a hundred years period from the 1830 's to the 1920 's, as well as their descendants. ${ }^{1}$ The Norwegian heritage speakers were gradually influenced by English (see Haugen 1953), and, apart from inter-sentential mixing, the resulting language mixing is characterized by mainly Norwegian structure and functional items paired with Norwegian and certain English content words. The question is how to model this mixing in a way that predicts the actually existing patterns, which is what we set out to do in this paper.

The paper is organized as follows. In section 2, we first introduce American Norwegian before we provide some relevant background on language mixing, focusing on word-internal mixing. Next, in section 3 we present and discuss the insertion-based exoskeletal model that we will use. Then, sections 4 and 5 present analyses of verb-internal and noun-internal mixing in American Norwegian, respectively, using the model presented in the previous section as our analytic tool. Section 6 concludes the paper.

\section{Language Mixing and American Norwegian}

In this section, we will first introduce the language, its speakers, and the corpus from which our data have been collected. Then we turn to a discussion of language mixing and clarify the basic assumptions we make in the present paper.

\subsection{American Norwegian}

The empirical basis of this paper consists of material from American Norwegian. American Norwegian is a heritage language spoken by Norwegian immigrants and their descendants. The immigrants first settled in the US during a hundred years' period starting from the first half of the 19th century (see Haugen 1953, Johannessen and Salmons 2015, and Page and Putnam 2015 for more information on American Norwegian). Typically, their descendants grew up speaking Norwegian in Norwegian communities in the Midwest and when they started school, their main language became English. Speakers of American Norwegian are very proud of their heritage and pride themselves on speaking Norwegian as well as possible. In our material, several American Norwegian speakers are engaged in a conversation, aided by a native Norwegian speaker, which makes the context very natural for using Norwegian. The heritage speakers' use and maintenance of Norwegian vary, ranging from

\footnotetext{
${ }^{1}$ Whether the first generation immigrants should be referred to as heritage speakers along with their descendants or not, is a subject of debate (Montrul 2008, 2016, Rothman 2009, Åfarli 2015a). In any case, our dataset does not comprise speech from first generation immigrants.
} 
very fluent speakers to speakers who struggle to find words and who use a lot of English. The amount of pauses and hesitations in the dialogues in the modern corpus (see below) also shows that speakers have lexical access issues, and as a result, often resort to English. This shows that they are mixing 'online', as it were, spontaneously and on the fly in the conversation, using both the Norwegian and English version of what appears to be the same concept. ${ }^{2}$

A lot of data material was collected by Einar Haugen in the 1930's and 1940's (see Haugen 1953) and Arnstein Hjelde in the 1980's (Hjelde 1992). Currently, however, an electronic database called the Corpus of American Norwegian Speech (CANS) is being created at the Text Laboratory at the University of Oslo, which includes material that has been collected in recent years, see Johannessen (2015). It is this newer material that our data come from, which consists of tagged spoken data from 50 speakers. This corpus is a rich source of American Norwegian mixing data that is wellsuited for our purposes. First, it comprises data collected over the past few years and therefore contains considerably more instances of language mixing compared to the data collected earlier, as the speakers are being ever more influenced by English. Moreover, it contains sound and video files together with transcriptions, which enables us to listen to the pronunciation of the inserted English item.

In American Norwegian, Norwegian is the main language and English is the secondary language. We use these terms as descriptive labels, not as theoretical primitives. As shown in (1) and (2), tense affixes are Norwegian and noun phrases exhibit Norwegian syntax and affixes, even when the lexical content morphemes are mixed from English. Also, Norwegian is a Verb Second (V2) language, whereas English is not. American Norwegian clauses mostly show V2 (see Eide and Hjelde 2015 for discussion), as clearly shown in (2). In the examples below, English spelling is used for English words, marked as bold. The information in parenthesis behind each example is a reference to the speaker in the CANS corpus who produced the utterance. ${ }^{3}$

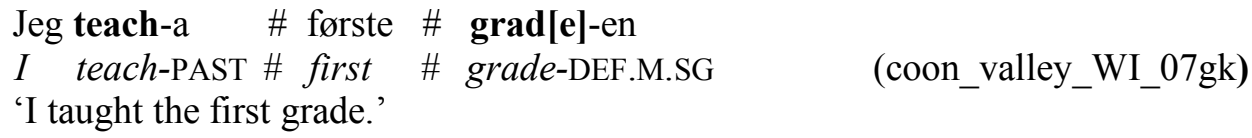

The overall tendency that can be observed in several types of language contact and mixing is the following (cf. Afarli 2015a). One of the languages involved is the main language while the other is the

\footnotetext{
${ }^{2}$ Factors like language dominance and proficiency are thus likely explanations to why speakers of American Norwegian use so many English items when speaking American Norwegian, as compared to a speaker of nonheritage Norwegian.

3 The following annotations are used in the glosses: \#: pause, DEF: definite, F: feminine, INDEF: indefinite, INF: infinitive, M: masculine, N: neuter, PAST: past tense, PL: plural, PRES: present tense, SG: singular.
} 
secondary language. The main language typically provides the overall grammatical structure of the utterances (e.g. as expressed through word order), as well as most of the lexical content morphemes and all the inflectional/functional morphemes. The secondary (or influencing) language occasionally provides lexical content morphemes, but not inflectional or functional morphemes. We can display the main pattern as in (3).
a. $\mathrm{L}_{\mathrm{SEC}}$
$+\quad$ INFL $_{\text {MAIN }}$
b. L LAIN
$+\quad$ INFL $_{\text {MAIN }}$
c. $\quad * \mathrm{~L}_{\mathrm{SEC}}$
$+\quad$ INFLSEC
d. $\quad * \mathrm{~L}_{\text {MAIN }}$
$+\quad$ INFL $_{S E C}$

(except in bigger mixed chunks) $^{4}$

The present paper is primarily concerned with word-internal mixing where lexical content items from a secondary language occur with inflectional morphemes from the main language, i.e., mixing of the type (3a).

\subsection{The grammar of language mixing}

In this paper, we use the general (and neutral) term language mixing, whereas a lot of the literature we will rely on uses code-switching. Code-switching is typically understood in a narrow sense as bilingual 'online' mixing, and there is substantial debate in the literature regarding whether or not certain types of mixing are to be considered code-switching or not. The focal point in the present paper is, as mentioned above, word-internal mixing, i.e., cases where parts of a given word are drawn from two different languages, and indeed the debate just referred to is especially heated when it comes to distinguishing between code-switches and loanwords (see e.g., Poplack, Sankoff and Miller 1988, Poplack and Dion 2012, Muysken 2000, Haspelmath 2009, Gardner-Chloros 2009). It is straightforward to assume that established loanwords are available for monolinguals as well as bilinguals, whereas one has to have some competence in an L2 in order to code-switch. What is not equally straightforward, is how - if at all - one can look at a single mixed lexical item spoken by a bilingual and decide for certain whether we are dealing with a loanword or an instance of codeswitching, see also Grimstad et al. (2014), Åfarli (2015a), and Grimstad (2017) for further discussion of this particular issue.

There are a number of stands on the code-switching versus loanword problem. Some scholars argue that due to inappropriate methodology, attempts at distinguishing between the two must fail (Eastman 1992, Johanson 1993, Thomason 2001, Winford 2003, Gardner-Chloros 2009). Others argue that the distinction is fuzzy or part of a continuum (Heath 1989, Myers-Scotton 1993, 2002, 2006,

\footnotetext{
${ }^{4}$ See Grimstad et al. (2014) for an example of how these bigger mixed chunks can be analyzed within this framework, and see Grimstad (2017) for more discussion of how our model can explain different types of language mixing. There is also another similar type of exception to the pattern (3c), namely the use of the English plural marker $-s$ with an English noun in an otherwise Norwegian noun phrase. An analysis of this phenomenon can be found in Riksem (in press) and Riksem et al. (2014); see also footnote 24.
} 
Field 2002, Clyne 2003, Thomason 2003, Treffers-Daller 2005, Haspelmath 2009). Yet others claim they can be distinguished and in fact are completely separate, non-related phenomena (Sankoff and Poplack 1981, Poplack and Dion 2012, MacSwan 1999, MacSwan and Colina 2014). In addition to loanwords, there is also what Poplack, Sankoff and Miller (1988) dub nonce borrowings; items that are borrowed spontaneously for the nonce. ${ }^{5}$

Several researchers, e.g., Myers-Scotton (1993) and Haspelmath (2009), have pointed out that the idea of nonce borrowing is straight out contradictory and thus dismissed it. Myers-Scotton, for instance, see borrowings as partly the result of a diachronic process where the borrowed form as a rule entered the language through code-switching, in which case the idea of a spontaneous nonce borrowing is impossible. However, how one sees this depends on the definition of code-switching and borrowing. As Gardner-Chloros (2009) points out, "code-switching” is a theoretical term, which ultimately can be allotted different meanings. The same goes for "borrowing," of course, so it is possible to define code-switching and borrowing in ways that do not necessitate a diachronic process. Muysken (2000: 69), for instance, states that "[c]ode-mixing involves inserting alien words or constituents into a clause; borrowing entering alien elements into a lexicon." Entering alien elements into the lexicon could be a gradual process given Muysken's definition as well, but it does not have to be.

A non-diachronic perspective is adopted by Poplack, MacSwan and others. In addition, both Sankoff and Poplack (1981) and MacSwan (1999), as well as all later instantiations of MacSwan's work, share the assumption that one can distinguish code-switches from borrowings by looking at how phonologically integrated the alien items are into the recipient language, the assumption being that whereas borrowings will have the recipient language phonology, code-switches retain the phonology of the donor language. ${ }^{6}$ Based on this, MacSwan claims that word-internal code-switching does not exist, ${ }^{7}$ and in MacSwan (2005) he goes through a series of posited counterexamples to that claim in order to show that they really are not code-switches, but rather borrowings. The general thrust of his arguments is that in every instance where there seems to be a word-internal switch, we are really faced with a borrowing where the borrowed item is phonologically integrated in the recipient language, or the switch is not really word-internal on closer inspection, but rather involving phrasal level affixation (MacSwan 2005, MacSwan and Colina 2014). We will not enter into an elaborate discussion of this issue, but we agree with Shana Poplack that phonological integration is a poor diagnostic for code-

\footnotetext{
${ }^{5}$ The term nonce borrowing was first coined by Weinreich 1953/1968 (Poplack 2015: 921), but with a different meaning.

${ }^{6}$ As of Poplack et al. (1988), Poplack and her associates have left this assumption behind as corpus studies showed that the phonology of borrowed items may in fact vary, meaning it cannot be used as a reliable criterion for distinguishing code-switches from borrowings.

${ }^{7}$ It seems Poplack and Sankoff (1981) also rules out word-internal code-switches, something which Muysken (2000: 78) also observes. However, Poplack (2012) says she never ruled out word-internal code-switching and that they are theoretically possible alongside nonce borrowings. As far as we can see, though, she does not say how her syntactic approach can accommodate that.
} 
switching or borrowing status, see the quote below from Poplack (2012: 647) where she discusses

French single words integrated into English:

[...] phonological integration is variable, increasing with frequency and listedness of the LOLI [lone other-language item]. [...] It matters that the unambiguous code-switches to English included in both calculations ALSO show variable phonological "integration". In other words, even when speaking English, words are sometimes rendered in French phonology. EACH of the categories - listed, unlisted, frequent, nonce, AS WELL AS CODE-SWITCHES TO ENGLISH - show some phonological integration and some failure to integrate. Phonological integration is GRADIENT. [...] as stated in PSM [Poplack, Sankoff \& Miller] (1988), and many times thereafter, phonological integration is a poor diagnostic for code-switching or borrowing status, precisely BECAUSE it occurs variably in all of them.

For this reason, we assume that phonological integration cannot be used as a reliable diagnostic. See Grimstad et al. (in press) for further discussion of MacSwan's approach. ${ }^{8}$

As will become evident in the course of this paper, our syntactic model will allow and predict word-internal code-switching or mixing. In a nutshell, since we adopt a non-lexicalist exoskeletal model with "syntax all the way down", the non-existence of word-internal mixing would actually require special explanation.

As to our general approach to language mixing, we want to point out explicitly that we adopt a so-called Null Theory approach (see, e.g., Pfaff 1979, Woolford 1984, Mahootian 1993, MacSwan 1999, 2000, 2005, and González-Vilbazo and López 2011, 2012) or a Constraint-free Approach (MacSwan 2014), i.e., an approach that claims that the same theory that accounts for monolingual data should account for language mixing as well. An advantage of this perspective is that language mixing is not something peripheral to the study of the language faculty, but rather, data from language mixing can inform the study of this faculty (cf. Muysken 2000, Chan 2008).

The opposite view claims that the analysis of language mixing phenomena requires additional theoretical primitives. For instance, Myers-Scotton $(1993,2002)$ argues that it is impossible to explain language mixing phenomena without assuming an asymmetry between what she calls a matrix language and an embedded language, which are considered theoretical primitives (see also Joshi 1985; Jake, Myers-Scotton and Gross 2002). In any given utterance, the matrix language is the main language of the speaker whereas the embedded language is a secondary language. This grammatical distinction is evident as the matrix language is responsible for major word order phenomena and for providing the inflectional/functional morphemes, whereas the secondary language occasionally contributes lexical content items. ${ }^{9}$ Given that we adopt a null theory approach, we will not make use of Myers-Scotton's notions, but rather informally refer to main and secondary languages as observational phenomena, not as theoretical primitives (cf. section 2.1).

\footnotetext{
${ }^{8}$ Note also that assuming the existence of word-internal code-switching would be in accordance with Poplack et al. (1988).

${ }^{9}$ The approach in Poplack $(1980,1981)$ and Sankoff and Poplack (1981) also proposes constraints that are unique to language mixing. See also Gumperz (1982).
} 


\section{A late-insertion-based exoskeletal model}

In this section, we will outline a new approach to grammar, namely a late-insertion-based exoskeletal model. For reasons of space, we will not review the evidence in favor of such a model. ${ }^{10}$ Instead we quote Marantz (2013: 153) where he says that current developments in linguistic theory

“... have shifted discussion away from verb classes and verb-centered argument structure to the detailed analysis of the way that structure is used to convey meaning in language, with verbs being integrated into the structure/meaning relations by contributing semantic content, mainly associated with their roots, to subparts of a structured meaning representation."

This stands in contrast to what has become a hallmark of some work within the Minimalist Program (Chomsky 1995), namely its lexicalist nature: syntactic structure is generated based on features on lexical and functional elements (see Adger 2003 for a textbook illustration where this is pursued in detail; see also Adger 2010, and Adger and Svenonius 2011). This feature-based approach has also been applied to intra-individual variation; see especially MacSwan (1999, 2000), King (2000), and Adger (2006).

In the exoskeletal model that we will be developing, formal features constitute the building blocks of syntactic structures, but the generation of structures is not driven by features on lexical items. Rather, functional features create a skeleton which is subject to insertion: Morphophonological exponents realizing functional features are inserted late, post narrow syntax, whereas lexical content items are inserted freely into designated positions (such as specifier and complement positions) in the syntactic structure.

Exoskeletal approaches constitute a family of models, even though the name originates with Borer's approach (Borer 2003, 2005a, b). We will argue for a combination of an exoskeletal theory of grammar with elements of Distributed Morphology (DM) (Halle and Marantz 1993, Marantz 1997, Harley and Noyer 1999, Embick and Noyer 2007). Rather than assuming one lexicon that the speaker/listener can access at the very beginning of the syntactic derivation, DM has distributed the content of the lexicon throughout the derivation, comprising three separate lists. This is illustrated in (4).

\footnotetext{
${ }^{10}$ See e.g. Borer (2005a, 2005b), and Lohndal (2014) for extensive argumentation in favor of one version of an exoskeletal model.
} 


\section{LISTS ACCESSED}

Access to Syntactic terminals

\section{STAGES OF THE DERIVATION}

Syntactic derivation

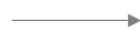

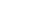


language or variety, another list for those belonging to the other, and a third list encompassing all the roots. The features that make up the abstract morphemes are part of a universal repository; and learning a language or variety is learning which features are "active" in that specific language, as well as how they bundle together, and then storing that information as specific abstract morphemes. Thus, if Norwegian makes use of the feature bundle $[+\mathrm{X},+\mathrm{Y},+\mathrm{Z}]$, and a particular speaker of Norwegian also speaks another language or variety which makes use of the exact same feature bundle, the same bundle will be stored in both lists of abstract morphemes. Roots/stems, on the other hand, are not components of a final list, and we can therefore always add new ones. This distinction between roots and abstract morphemes reflects the classic division between open and closed class items.

There are two options for the generation of syntactic structures (templates/frames). Either they are generated by the functional features, or alternatively Merge operates freely (Chomsky 2004, Boeckx 2014). We will not take a stand regarding this particular question. Rather, we want to look into the consequences for language mixing of a model such as the one proposed here, where abstract syntactic structures are generated prior to any lexical insertion. Let us look at an abstract and simplified representation of the argument structure domain of a clause. [ ] denotes a feature bundle.

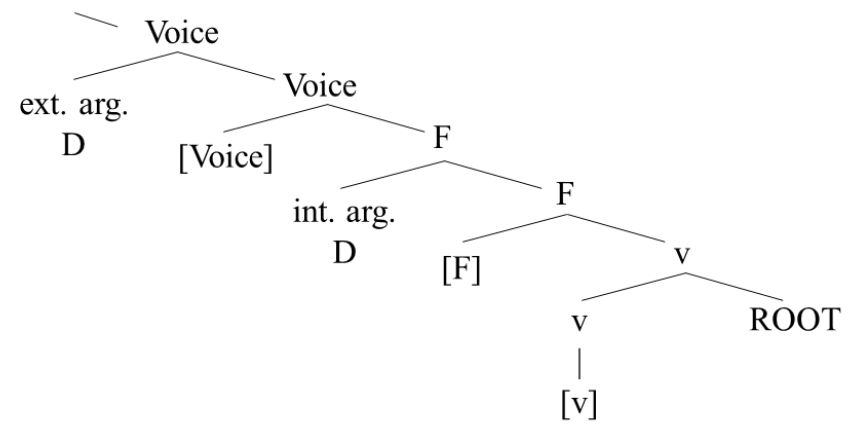

This structure builds on Lohndal $(2012,2014)$, where the abstract verb position is generated prior to the functional structure that introduces arguments. Both the internal and the external arguments are introduced into the structure by way of dedicated functional projections. Other structures such as in Borer (2005a, b), Ramchand (2008), Bowers (2010), Alexiadou, Anagnostopoulou, and Schäfer (2015) or Åfarli and Subbarao (in press) are also compatible with what follows; we are simply using (5) for ease of exposition.

We will follow DM in assuming that both roots/stems and abstract morphemes/functional features are abstract units, which do not get their final phonological content until after Spell-Out to the phonological interface (see e.g., Harley 2014 for an explicit way of encoding this). Another way of putting it is to say that the exponents of all lexical material (in the wide sense, comprising both functional and content items) are inserted late. This process is known in DM as Vocabulary Insertion, and grants access to the second list, the Vocabulary. The Vocabulary consists of the phonological 
exponents, or Vocabulary Items (in DM), of the different abstract roots/stems and abstract morphemes, and crucially concerning the latter, we assume that each language has a repertoire of functional exponents that are tailor-made to fit the features of the abstract structure.

The resulting picture is one in which we have an abstract syntactic structure and a selection of phonological exponents that can be inserted. Insertion of an exponent (e.g., a verb or noun stem) for an abstract root/stem occurs without any syntactic constraints, as the syntactic positions in which stems are inserted make no featural demands regarding their content apart from the constraint that stems can only be inserted in environments where the given lexical category is licit. Vocabulary Insertion into functional terminals, on the other hand, is competitive, following the rules of exponence summarized in the Subset Principle (Halle 1997: 428), which reads as follows:

The phonological exponent of a Vocabulary Item is inserted into a position if the item matches all or a subset of the features specified in that position. Insertion does not take place if the Vocabulary item contains features not present in the morpheme. Where several Vocabulary Items meet the conditions of insertion, the item matching the greatest number of features specified in the terminal morpheme must be chosen.

The assumption that the functional exponents of a given language are tailor-made to fit the functional features of that same language, gives them precedence in the process of Spell-Out. Thus, competition for insertion regulated by the Subset Principle will as a main rule be confined to the functional exponents belonging to that language. A notion of "language mode" can be invoked in this connection (see Grosjean 2008, 2013 for a different yet related use of this notion; see Grimstad 2017 for more discussion of exceptions to this pattern). The selection of functional features or feature bundles from the language-specific list of abstract morphemes already implies that the speaker will be in a certain language mode, and as far as selection of functional exponents is concerned, that language mode will also determine the selection of functional exponents. On the other hand, even though exponents for abstract roots/stems are also marked in the encyclopedia as belonging to a certain language, such exponents are not tailor-made to fit abstract morphemes. Thus, insertion of a stem is at the outset free and can take place from any language that the speaker has internalized.

We can now use this to explain why we can get the pattern in (3a), shown earlier. As seen in (3c) and (3d), the exponents of abstract functional morphemes usually come from the main language, not the secondary one. In the present context of American Norwegian, this amounts to saying that the functional vocabulary primarily comes from Norwegian and not from English. We assume that these speakers are in American Norwegian "language mode", and we further assume that the main language 
builds the structure. Thus, the feature bundles that are part of the structure come from the Norwegian list of abstract morphemes. Abstractly, this can be illustrated as in (6). ${ }^{11}$

(6)

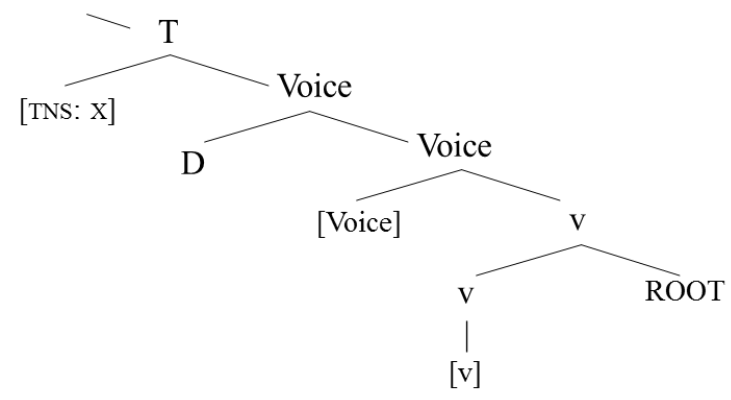

(6) shows the structure of a simple intransitive sentence in Norwegian. Focusing on the tense-verb relation and simplifying somewhat, we assume that the tense feature is generated under T. Given the Subset Principle, the functional exponent that will be subject to vocabulary insertion in any functional position has to match the features of the underlying abstract morpheme, without contributing features not specified by the structure. As suggested above, a structure built by the main language Norwegian will typically favor the Norwegian functional exponents. The stem, on the other hand, is inserted without such restrictions, and acquires tense by obligatory movement through Voice to $\mathrm{T}$. This means that content items associated with any language can be inserted, since a given lexical item or stem is not tailor-made to fit a specific feature bundle. This process and analyses of language mixing are discussed and exemplified in more detail in sections 4 and 5.

At least for English-Norwegian mixing, we tentatively assume that roots are not mixed on their own, in effect making the stem (categorizer head + root) the smallest element that is mixed. The fact that derived stems from English (like e.g. basement, township, building) are easily mixed into American Norwegian indicates that stems can be mixed in any case, so the strong hypothesis is that only stems can be mixed, although the weaker hypothesis that both roots and stems can be mixed is compatible with our analysis. ${ }^{12}$

It is important that the theory is exoskeletal in the sense that it takes seriously the notion of abstract syntactic structures that are generated based on features that are independent of lexical items. Not all versions of DM go that far, and we also do not want to commit ourselves to all properties of $\mathrm{DM}$, as our data do not readily speak to many of the mechanisms suggested in the literature (fusion,

\footnotetext{
${ }^{11}$ This does not prevent instances of cross-linguistic interference from English at the level of syntactic structure. That is, it is known that aspects of English syntax emerge, to different degrees, in the syntax of American Norwegian speakers (see e.g., the collection of papers in Johannessen and Salmons 2015). In our terms, this means that they are employing fragments of an English underlying structure, which is to be expected when the heritage language becomes weaker or attrited.

${ }^{12}$ This also entails that when an English root appears in a compound, like in telefoncompany 'telephone company', the root $\sqrt{ }$ COMPANY is categorized as a noun before it merges with the first part of the compound.
} 
fission, impoverishment, and so on). The crucial ingredients from DM that we rely on are roots being categorized by combination with a category-defining head, and the restrictions in the process of late insertion of morphophonological material.

This outlines the model we will be using. We now turn to word-internal language mixing in the following two sections, and how this specific model can account for the mixing patterns we observe in American Norwegian.

\section{Language mixing inside verbs in American Norwegian}

Let us consider how we can employ the model developed in section 3 to analyze word-internal mixing data from American Norwegian. We will first look at verbs in this section, and then at nouns in section 5 .

The examples in (7) illustrate verb-internal mixing. As in the previous examples, the index in parenthesis refers to the speaker in the CANS corpus who uttered that specific phrase. Also, English words are written using English spelling. Notice that even though the examples are given as single words, they are actually found within a larger discourse that occurs in Norwegian.
a. spend-e
spend-INF
'to spend'
(blair_WI_02gm)
h. rais[e]-er
raise-PRES
'raise(s)'
(blair_WI_01gm)
o. telephon[e]-a
telephone-PAST
'telephoned'
(harmony_MN_01gk)
b. bother-e
bother-INF
i. rent-er
rent-PRES
'rent(s)'
'to bother'
(coon_valley_WI_02gm)
p. $\quad \operatorname{car}[\mathbf{e}]-\mathrm{a}$
care-PAST
'cared'
c. figur[e]-e ut
figure-INF out
'to figure out'
(blair_WI_01gm)
j. pre-empt-er
pre-empt-PRES
'pre-empt(s)'
(harmony_MN_01gk)
q. tight-a
tight-PAST
'tighted'
(westby_WI_01gm)
d. harvest-e
harvest-INF
'to harvest'
(coon_valley_WI_02gm)
k. hunt-er
hunt-PRES
'hunt(s)
(coon_valley_WI_04gm)
r. catch-a
catch-PAST
'caught'
(sunburg_MN_03gm)
e. cultivat[e]-e
cultivate-INF
'to cultivate'
(coon_valley_WI_04gm)
1. feed-er
feed-PRES
'feed(s)'
(spring_grove_MN_05gm)
s. watch-a
watch-PAST
'watched'
(sunburg_MN_03gm) 
f. shut-e

shut-INF

'to shut'

(coon_valley_WI_04gm)

g. count-e

count-INF

'to count'

(sunburg_MN_03gm) m. retir[e]-a

retire-PAST

'retired'

(coon_valley_WI_06gm)

n. visit-a

visit-PAST

'visited'

(blair_WI_01gm) t. walk-te

walk-PAST

'walked'

(rushford_MN_01gm)

u. rais[e]-te

raise-PAST

'raised'

(blair_WI_01gm)

As illustrated, even though an English stem is used in the American Norwegian examples, the affixes are not English, but rather the ones used in Norwegian (see also Åfarli 2015b and Grimstad (2017) for a discussion of this phenomenon). ${ }^{13}$ How can we account for this?

A structure for the example in (7i), renter, will be as in (8), where the Vocabulary Item or exponent has been inserted to make it easier to read the structure. In the syntax, importantly, there are only feature bundles and abstract stems, i.e., categorizers and roots. Note that only the relevant features are shown, and renter is the complex spell-out of the PRES-feature, along with the abstract stem.

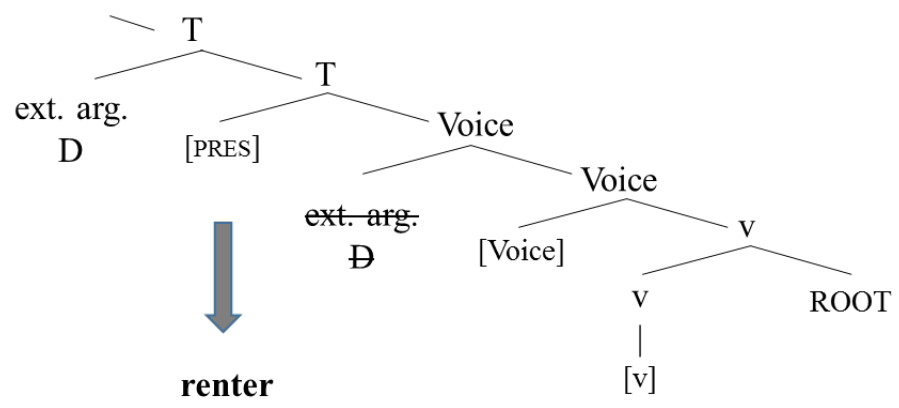

In this case, the verbal stem rent is inserted and subsequently moves from the base position through Voice until it picks up the inflectional morpheme in T. Not included here is that together, the verb and the inflectional ending would then move to $\mathrm{C}$, since American Norwegian conforms to the V2 rule.

Importantly, the exponent of this complex is renter, with a Norwegian tense inflection, -er, not rent or rents, with an English one. In order to explain why this is a pattern that we observe for all

\footnotetext{
${ }^{13}$ Our hypothesis is that the speakers use English inflections only when the main language is American English, i.e. they are consciously speaking English as opposed to American Norwegian. We assume that they are doing so either when the entire utterance is English, or, in the case of lone English items in otherwise American Norwegian utterances, when those are accompanied by discourse flagging. This could be metalinguistic commentary, hesitation, pausing and other indications suggesting the speaker was uncertain what to say. When they then utter an English word with English inflection, we assume they have failed to remember the correct American Norwegian word and switched to speaking English instead (even for just the one word). See Grimstad (2017) for further discussion of this, and Poplack, Sankoff and Miller (1988: 54), and Muysken (2000: 101-102) for similar conclusions.
} 
mixed verbs in American Norwegian, as opposed to a random coincidence, we have to look at the corresponding English structure. (9a) shows the relevant abstract structure with English feature bundles, and in (9b), we have inserted exponents.

(9)

a.

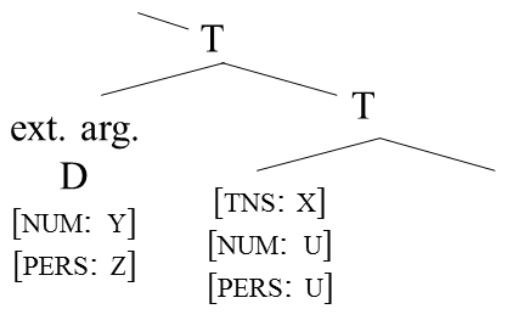

b.

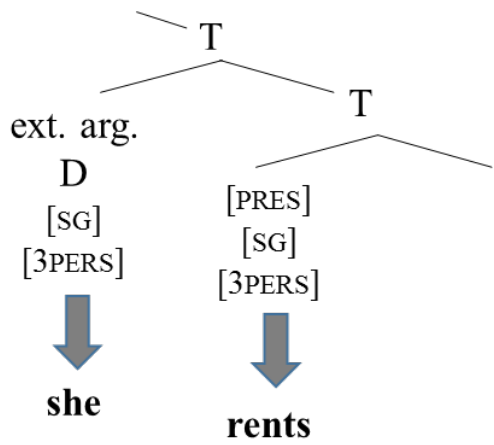

An important difference between English and Norwegian verbal structures is the fact that English has subject-verb agreement. This means that, unlike Norwegian, the English T has unvalued features for number and person that have to be valued by features of the external argument. When the external argument has the features [NUM: SG, PERS: 3], as in (9b), the exponent of T is rents with an $-s$. Had the external argument contained any other feature combination, however, the exponent would have been rent. As we recall from the abstract Norwegian structure in (6), we do not assume that the feature bundle of $\mathrm{T}$ used in Norwegian includes unvalued features for number and person, simply because Norwegian does not display subject-verb agreement. A Norwegian T has only a tense feature. Subsequently, following the Subset Principle, English exponents are ruled out as possible phonological exponents of the feature in the Norwegian T projection, seeing as they include features for number and person that are not called for in the structure. ${ }^{14}$

\section{Language mixing inside nouns in American Norwegian}

In this section, we discuss word-internal language mixing in the nominal domain. (10) shows some examples from CANS. Like before, the examples are given as single words, but they actually occur within a larger Norwegian discourse. Note that gender is not fixed across speakers, and it is not in

\footnotetext{
${ }^{14}$ It is worth noting that one also could assume that all languages have subject-verb agreement, but that some languages, such as Norwegian, have identical exponents for all feature combinations. If that were the case, the Norwegian and English exponents could possibly be equally well-matched, meaning the syntax would pose no restrictions on the insertion of any of them. As suggested in section 3, even in that case exponents from the main language are most likely to be chosen over those from the secondary language. The reason for this is that the speaker, being in a certain "language mode" determined by the main language, will also select functional exponents from that same language.
} 
general identical to their Norwegian translational equivalents; see Grimstad et al. (2016) for discussion.
a. road-en
road-DEF.SG.M
'the road'
(webster_SD_02gm)
h. field-a
field-DEF.SG.F
(westby_WI_02gm)
'the field'
b. choir-en
choir-DEF.SG.M
'the choir'
(coon_valley_WI_07gk)
i. voting-a
voting-DEF.SG.F
'the voting'
(westby_WI_01gm)
o. kid-er $^{15}$
kid-INDEF.PL.M
'kids'
(portland_ND_01gm)
p. mower-e $\mathrm{e}^{16}$
mower-INDEF.PL.M
'mowers'
(coon_valley_WI_06gm)
c. ferry-en
ferry-DEF.SG.M
'the ferry'
(harmony_MN_04gm)
j. $\quad$ stuff-et
stuff-DEF.SG.N
'the stuff'
(blair_WI_07gm)
q. sportsgam [e]-ene
sportsgam[e]-DEF.PL.M
'the sportsgames'
(westby_WI_02gm)
d. graveyard-en
graveyard-DEF.SG.M
'the graveyard'
k. cover-et
cover-DEF.SG.N
'the cover'
(blair_WI_07gm)
(coon_valley_WI_04gm)
r. $\quad$ farmer-ne $e^{17}$
farmer-DEF.PL.M
'the farmers'
(coon_valley_WI_03gm)
e. squirrel-en
squirrel-DEF.SG.M
'the squirrel'
(coon_valley_WI_02gm)
1. shed-et
shed-DEF.SG.N
'the shed'
(westby_WI_06gm)
s. fenc[e]-a
fenc[e]-DEF.PL.N
'the fences'
(coon_valley_WI_06gm)
f. fair-a
fair-DEF.SG.F
'the fair'
(coon_valley_WI_06gm)
m. pastur[e]-et
pastur[e]-DEF.SG.N
'the pasture'
t. tobakkshed-a
tobacco shed-DEF.PL.N
'the tobacco sheds'
(coon_valley_WI_03gm)
(coon_valley_WI_06gm)
g. bluff-a ${ }^{18}$
bluff-DEF.SG.F
'the bluff'
(westby_WI_01gm)
n. terrac[e]-er
terrac[e]-INDEF.PL.M
'terraces'
(coon_valley_WI_03gm)

Parallel to the verbs, in all examples in (10) English stems are used, whereas the functional suffixes are Norwegian. These suffixes show the categories that Norwegian nouns are inflected for:

\footnotetext{
${ }^{15}$ This example is transcribed kidder in the corpus, the double consonant being common for similar words in Norwegian orthography.

${ }^{16}$ When the stem ends in $-e r$ the [INDF, PL, M] suffix is realized as $-e$ in Norwegian.

${ }^{17}$ When the stem ends in -er the [DEF, PL, M] suffix is realized as -ne in Norwegian.

${ }^{18}$ This noun is also found once with masculine gender: en bluff (westby_WI_06gm).
} 
definiteness, number and gender. ${ }^{19}$ Definiteness and gender are particularly interesting in these data, as these represent structural differences between the two languages: While both definiteness and gender are realized by the functional suffix in Norwegian, definiteness in English is a feature of D alone, and gender is an alien category to English nouns. A pattern of the type exemplified throughout (10) would thus not be predicted by a lexicalist model, as the English lexical items could not be expected to provide such features. ${ }^{20}$

Our exoskeletal model fares better. In this model, definiteness, number and gender are part of the structural outfit of the Norwegian nominal phrase, and an English stem, when mixed into American Norwegian, will acquire the relevant features by virtue of being inserted into a structure that provides them. The abstract structure is shown in (11), and is based on the work on Norwegian DPs by Julien (2005), although with some substantial alterations (see Riksem in press for discussion).

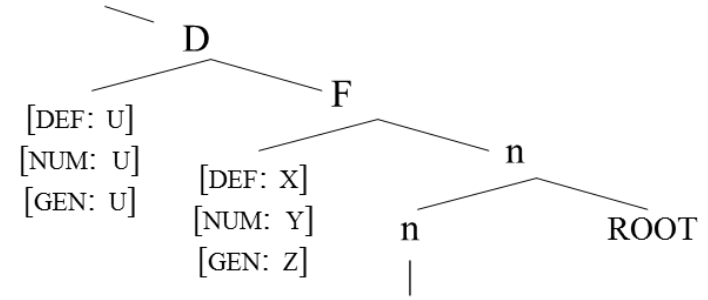

$[\mathrm{n}]$

The components of the structure are the abstract nominal stem $\mathrm{n}$, consisting of a root and a categorizer, a functional projection F, comprising (postnominally suffixed) definiteness, number and gender, and the $\mathrm{D}$ projection (prenominal inflected determiners). As discussed in section 3, the abstract nominal stem has a noun stem as its exponent, whereas the feature bundle under $\mathrm{F}$ will be realized in accordance with the Subset Principle. D holds a similar feature bundle consisting of corresponding unvalued features. These will be valued through Agree (see Julien 2005). As the focus of this paper is word-internal mixing, our main concern is the stem and the functional projection $\mathrm{F}$, since the exponent of $F$ will be suffixed to the stem as it moves to F. Notice however that Norwegian DPs may be otherwise quite complex, involving adjectives, weak quantifiers, post- or prenominal possessors and post-nominal PPs (see Julien 2005 for discussion).

As mentioned previously, definiteness and gender are especially interesting in language mixing between Norwegian and English. Definiteness in Norwegian is realized not only in the

\footnotetext{
${ }^{19}$ Notice that there is a debate concerning whether the functional suffix in Norwegian noun phrases is a genuine gender marker or rather a marker for declension class (see Enger 2004, and Lohndal and Westergaard 2016 for discussion). We assume that gender is reflected in the suffix.

${ }^{20}$ An alternative consistent with the lexicalist approach is to assume that English items are doubly represented in the lexicon: One representation with English features, and one with Norwegian ones. For reasons of space, we will not discuss such an option further, but we notice that such an analysis would imply a more complex analysis than the one we propose.
} 
determiner, as in English, but also through the suffix ${ }^{21}$ which distinguishes the Norwegian nominal structure from the English equivalent. Seeing that the English stems in (10) occur with definiteness realized as a suffix supports the analysis that these are inserted into a Norwegian structure.

Concerning gender, there are a number of analytical proposals in the literature. These can roughly be split into two broad alternatives. The first alternative is to analyze gender as an inherent feature of the root itself, or possibly as a feature of the categorizing head n (see e.g. Alexiadou 2004; Kramer 2014), whereas a second alternative is analyzing it as a property of the higher functional structure of the noun phrase, either as head of its own projection (Picallo 1991, 2008; Nygård and Afarli 2015) or as a feature of the number projection (Ritter 1993). Language mixing, like the American Norwegian examples in (10), provides evidence against the former alternative. Considering that roots are devoid of grammatical features, as discussed in section 3, these cannot provide a gender feature. Furthermore, assuming that the smallest item being mixed is the stem, makes it difficult to explain how English noun stems, which are typically not associated with a gender feature, could provide such a feature in the mixed phrases.

We thus assume that gender must be located in the higher functional structure, in accordance with the second alternative sketched above. ${ }^{22}$ However, our available data do not clearly reveal the internal structure of the lower part of the noun phrase and the specific position of gender. Neither are such details crucial to the present analysis. We therefore propose the functional projection $\mathrm{F}$ which holds a bundle consisting of all three relevant features, and the interplay between these will regulate which suffix is to be inserted.

Consider now how the model in (11) can account for the language mixing data in (10). As we are concerned with word-internal mixing, we only discuss the lower part of the structure, but keep in mind that this enters into a larger DP structure. (12) shows the structure of (10a), roaden.

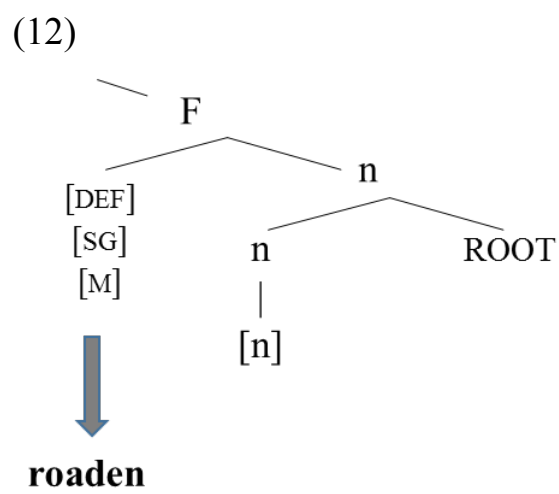

\footnotetext{
21 A consequence of this structure is also the phenomenon of double definiteness, i.e. the co-occurrence of definiteness both in F and D (Julien 2005).

${ }^{22}$ If the particular gender that a noun has is not an inherent property of the noun stem, an interesting question arises concerning the assignment of a specific gender to a given noun. We cannot discuss this question here, but see Nygård and Åfarli (2015) for an analysis of this perennial problem which is consistent with our assumption that gender is located in the higher functional structure of the noun phrase.
} 
The functional feature bundle in (12) is composed of the features definite, singular and masculine. In the process of spell-out, all functional exponents compete for insertion into this position, but the Norwegian exponent -en will win due to being the more specified alternative, since it is specified for all three features. The stem, on the other hand, is inserted without such a feature requirement, and it moves to $F$ to pick up the suffix, yielding the complex form roaden. The same process will be applicable to the remaining data in (10), only with the functional exponent varying according to the feature composition of F. Note also that all three genders are used in the mixed noun phrases, which eliminates the possibility of this being the result of having a default gender in the case of language mixing. ${ }^{23}$

The number feature represents a type of similarity between English and Norwegian nominal structures, as plurality is expressed by suffixes in both languages. Nevertheless, also mixed plural noun phrases have a Norwegian functional suffix, cf. (10n-t), which is predicted since Norwegian plural suffixes also vary according to definiteness and gender. Thus, as Norwegian functional exponents are specified for all three features, and the available English functional suffix $(-s)$ is only specified for plurality, the Norwegian exponent is preferred and inserted. ${ }^{24}$ The structure of $(100)$, kider, is shown in (13).

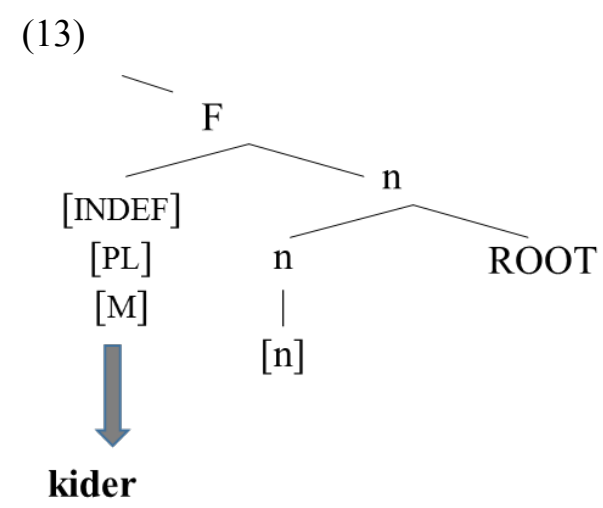

\section{Conclusion}

\footnotetext{
${ }^{23}$ Gender assignment in language mixing might also be hypothesized to be the result of assignment based on the gender of the corresponding stem in the other language, in this case a translation of the Norwegian equivalent noun stem. However, this proposal does not coincide with the AmNo data, e.g., choiren, $\mathrm{M}$ (coon_valley_WI_07gk) - koret, N (Norwegian); ferryen, M (harmony_MN_04gm) - ferga, F (Norwegian); et title, $\mathrm{N}$ (stillwater_MN_01gm) - ein tittel, M (Norwegian).

${ }^{24}$ However, there are cases, observed both in CANS and in earlier American Norwegian material (Haugen 1953; Hjelde 1992), where the English plural $-s$ is in fact used in similar cases. For reasons of space we cannot discuss this here, but we consider this to be the consequence of the extensive language mixing and its impact on the composition of the feature bundle. See Riksem (in press) for a discussion of how this phenomenon can be analyzed in an exoskeletal model, still in keeping with the Subset Principle.
} 
This paper has presented case-studies of language mixing within verbs and nouns in the heritage language American Norwegian, whereby English and Norwegian are mixed in a rule-governed way. The paper builds on data from the newly established Corpus of American Norwegian Speech and argues in favor of an exoskeletal approach to language mixing. This approach distinguishes between abstract syntactic feature bundles and the morphophonological realization of these bundles, much like in late insertion approaches to morphology. A main goal of the paper has been to show how the word internal mixing patterns observed in American Norwegian can be analyzed in a model of grammar employing an exoskeletal approach with a late insertion approach to morphology. We have seen how features together with the Subset Principle are able to adequately account for the systematic patterns seen in the data.

\section{Acknowledgements}

We would like to thank two anonymous reviewers for helpful comments and suggestions.

\section{References}

Adger, David. 2003. Core Syntax. Oxford: Oxford University Press.

Adger, David. 2006. Combinatorial Variation. Journal of Linguistics 42: 503-530.

Adger, David. 2010. A minimalist theory of feature structure. In Features: Perspectives on a key notion in linguistics, eds. Anna Kibort and Greville Corbett, 185-218. Oxford: Oxford University Press.

Adger, David and Peter Svenonius. 2011. Features in Minimalist Syntax. In The Oxford Handbook of Linguistic Minimalism, ed. Cedric Boeckx, 27-51. Oxford: Oxford University Press.

Åfarli, Tor A. 2015a. A Syntactic Model for the Analysis of Language Mixing Phenomena: American Norwegian and Beyond. In Moribund Germanic Heritage Languages in North America, eds. B. Richard Page and Michael T. Putnam, 12-33. Leiden: Brill.

Åfarli, Tor A. 2015b. Hybrid verb forms in American Norwegian and the analysis of the syntactic relation between the verb and its tense. In German Heritage Languages in North America, eds. Janne Bondi Johannessen and Joseph C. Salmons, 161-177. Amsterdam/Philadelphia: John Benjamins.

Åfarli, Tor A. and Subbarao, Karumuri V. (in press). Models of grammar and the outcomes of longterm language contact: Language mixing in Dakkhini. In Diverse scenarios of syntactic complexity: inter and intra typological diversity, eds. Zarina Estrada-Fernández, Albert Alvarez-Gonzalez, \& Claudine Chamoreau. Amsterdam: John Benjamins.

Alexiadou, Artemis. 2004. Inflection class, gender and DP-internal structure. In Explorations in Nominal Inflection, eds. Gereon Müller, Lutz Gunkel, and Gisela Zifonun, 21-50. Berlin: Mouton de Gruyter. 
Alexiadou, Artemis, Hagit Borer and Florian Schäfer (Eds.). 2014. The Syntax of Roots and the Roots of Syntax. Oxford: Oxford University Press.

Alexiadou, Artemis, Elena Anagnostopoulou, and Florian Schäfer. 2015. External arguments in transitivity alternations: a layering approach. Oxford: Oxford University Press.

Arad, Maya. 2005. Roots and Patterns: Hebrew Morpho-syntax. Dordrecht: Springer.

Boeckx, Cedric. 2014. Elementary Syntactic Structures. Cambridge: Cambridge University Press.

Borer, Hagit. 2003. Exo-skeletal vs. Endo-Skeletal Explanations: Syntactic Projections and the Lexicon. In The Nature of Explanation in Linguistic Theory, eds. John Moore and Maria Polinsky, 31-67. Stanford: CSLI Publications.

Borer, Hagit. 2005a. Structuring Sense I: In Name Only. Oxford: Oxford University Press.

Borer, Hagit. 2005b. Structuring Sense II: The Normal Course of Events. Oxford: Oxford University Press.

Bowers, John. 2010. Arguments as Relations. Cambridge, MA: MIT Press.

Chan, Brian Hok-Shing. 2008. Code-switching, word order and the lexical/functional category distinction. Lingua 118: 777-809.

Chomsky, Noam. 1995. The Minimalist Program. Cambridge, MA: The MIT Press.

Chomsky, Noam. 2004. Beyond Explanatory Adequacy. In Structures and Beyond: The Cartography of Syntactic Structures, ed. Adriana Belletti, 104-131. Oxford: Oxford University Press.

Clyne, Michael. 2003. Dynamics of language contact. Cambridge: Cambridge University Press.

Eastman, Carol M. 1992. Codeswitching as an urban language-contact phenomenon. Journal of Multilingual and Multicultural Development 12: 1-17.

Eide, Kristin Melum and Arnstein Hjelde. 2015. Verb Second and Finiteness Morphology in Norwegian Heritage Language of the American Midwest. In Moribund Germanic Heritage Languages in North America: Theoretical Perspectives and Empirical Findings, eds. B. Richard Page and Michael T. Putnam, 64-101. Leiden: Brill.

Embick, David and Rolf Noyer. 2007. Distributed Morphology and the syntax morphology interface. In The Oxford Handbook of Linguistic Interfaces, eds. Gillian Ramchand and Charles Reiss, 289-324. Oxford: Oxford University Press.

Enger, Hans-Olav. 2004. On the relation between gender and declension: A diachronic perspective from Norwegian. Studies in Language 28: 51-82.

Field, Frederic. 2002. Linguistic borrowing in bilingual contexts. Amsterdam: John Benjamins. Gardner-Chloros, Penelope. 2009. Code-switching. Cambridge: Cambridge University Press. González-Vilbazo, Kay and Luis López. 2011. Some properties of light verbs in code switching. Lingua 121: 832-850.

González-Vilbazo, Kay and Luis López. 2012. Little v and parametric variation. Natural Language and Linguistic Theory 30: 33-77. 
Grimstad, Maren B. 2017. The codeswitching/borrowing debate: Evidence from English-origin verbs in American Norwegian. Lingue e Linguaggio XVI (1): 3-34. doi: 10.1418/86999

Grimstad, Maren Berg, Terje Lohndal, and Tor A. Åfarli. 2014. Language mixing and exoskeletal theory: A case study of word-internal mixing in American Norwegian. Nordlyd 41 (2): 213 237.

Grimstad, Maren Berg, Brita R. Riksem, Terje Lohndal, and Tor A. Åfarli. 2016. Word-internal language mixing, late insertion, and underspecification. Poster presented at The 31st Comparative Germanic Syntax Workshop, Stellenbosch University, December 2.

Grimstad, Maren B., Brita R. Riksem, Terje Lohndal, and Tor A. Åfarli. In press. Lexicalist vs. exoskeletal approaches to language mixing. The Linguistic Review.

Grosjean, Francois. 2008. Studying Bilinguals. Oxford: Oxford University Press.

Grosjean, Francois. 2013. Bilingual and Monolingual Language Modes. In Encyclopedia of Applied Linguistics, ed. Carol A. Chapelle, 1-9. Malden: Blackwell.

Gumperz, John. 1982. Discourse Strategies. Cambridge: Cambridge University Press.

Halle, Morris. 1997. Distributed morphology: Impoverishment and fission. In MITWPL 30: PF:

Papers at the Interface, eds. Benjamin Bruening, Yoonjung Kang, and Martha McGinnis, 425449. Cambridge: MITWPL.

Halle, Morris and Alex Marantz. 1993. Distributed Morphology and the Pieces of Inflection. In The View from Building 20: Essays in Linguistics in Honor of Sylvain Bromberger, eds. Kenneth Hale and Samuel Jay Keyser, 111-176. Cambridge, MA: The MIT Press.

Harley, Heidi. 2014. On the Identity of Roots. Theoretical Linguistics 40: 225-276

Harley, Heidi and Rolf Noyer. 1999. Distributed Morphology. Glot International 4: 3-9.

Haspelmath, Martin. 2009. Lexical borrowing: Concepts and Issues. In Loanwords in the world's languages: A comparative handbook, eds. Martin Haspelmath and Uri Tadmor, 35-54. Berlin: Mouton de Gruyter.

Haugen, Einar. 1953. The Norwegian Language in America. Philadelphia: University of Philadelphia Press.

Heath, Jeffrey. 1989. From code-switching to borrowing: A case study of Moroccan Arabic. London: Kegan Paul International.

Hjelde, Arnstein. 1992. Trøndsk talemål i Amerika. Trondheim: Tapir.

Jake, Janice L., Carol Myers-Scotton and Steven Gross. 2002. Making a minimalist approach to codeswitching work: Adding the Matrix Language. Bilingualism: Language and Cognition 5: 69-91.

Johannessen, Janne Bondi. 2015. The Corpus of American Norwegian Speech (CANS). In Proceedings of the 20th Nordic Conference of Computational Linguistics, ed. Béata Megyesi, NODALIDA 2015, May 11-13, 2015, Vilnius, Lithuania. NEALT Proceedings Series 23. 
Johannessen, Janne Bondi and Joe Salmons (Eds.). 2015. Germanic heritage languages in North America: Acquisition, attrition and change. Amsterdam: John Benjamins.

Johanson, Lars. 1993. Code-copying in Immigrant Turkish. In Immigrant languages in Europe, eds. Guus Extra and Ludo Verhoeven, 197-221. Clevedon: Multilingual Matters.

Joshi, Aravind K. 1985. Processing of sentences with intrasentential code switching. In Natural Language Parsing: Psychological, Computational, and Theoretical Perspectives, ed. David Dowty, Lauri Karttunen, and Arnold Zwicky, 190-205. Cambridge: Cambridge University Press. Julien, Marit. 2005. Nominal Phrases from a Scandinavian Perspective. Amsterdam: John Benjamins. King, Ruth. 2000. The Lexical Basis of Grammatical Borrowing: A Prince Edward Island French Case Study. Amsterdam: John Benjamins.

Kramer, Ruth. 2014. Gender in Amharic: a morphosyntactic approach to natural and grammatical gender. Language Sciences 43: 102-115.

Lohndal, Terje. 2012. Without Specifiers: Phrase Structure and Argument Structure. Doctoral dissertation, University of Maryland.

Lohndal, Terje. 2014. Phrase structure and argument structure: A case-study of the syntax semantics interface. Oxford: Oxford University Press.

Lohndal, Terje and Marit Westergaard. 2016. Grammatical Gender in American Norwegian Heritage Language: Stability or Attrition? Frontiers in Psychology. doi: http://dx.doi.org/10.3389/fpsyg.2016.00344

MacSwan, Jeff. 1999. A minimalist approach to intra-sentential code-switching. New York: Garland.

MacSwan, Jeff. 2000. The architecture of the bilingual faculty: evidence from intrasentential code switching. Bilingualism 3: 37-54.

MacSwan, Jeff. 2005. Codeswitching and generative grammar: A critique of the MLF model and some remarks on «modified minimalism». Bilingualism: Language and Cognition 8: 1-22.

MacSwan, Jeff and Sonia Colina 2014. Some Consequences of Language Design: Codeswitching and the PF Interface. In Grammatical Theory and Bilingual Codeswitching, ed. Jeff MacSwan, 185210. Cambridge, MA: MIT Press.

Mahootian, Shahrzad. 1993. A null theory of code-switching. Doctoral dissertation, Northwestern University.

Marantz, Alec. 1997. No Escape from Syntax: Don't Try Morphological Analysis in the Privacy of Your Own Lexicon. In Proceedings of the 21st Penn Linguistics Colloquium, eds. Alexis Dimitriadis, Laura Siegel, Clarissa Surek-Clark, and Alexander Williams, 201-225. University of Pennsylvania, UPenn Working Papers in Linguistics.

Marantz, Alec. 2013. Verbal argument structure: Events and participants. Lingua 130: 152-168.

Montrul, Silvina. 2008. Incomplete Acquisition in Bilingualism: Re-examining the Age Factor. Amsterdam: John Benjamins. 
Montrul, Silvina. 2016. The Acquisition of Heritage Languages. Cambridge: Cambridge University Press.

Muysken, Pieter. 2000. Bilingual Speech. A Typology of Code-Mixing. Cambridge: Cambridge University Press.

Myers-Scotton, Carol. 1993. Duelling Languages: Grammatical Structure in Code Switching. Oxford: Oxford University Press.

Myers-Scotton, Carol. 2002. Contact Linguistics: Bilingual Encounters and Grammatical Outcomes. Oxford: Oxford University Press.

Myers-Scotton, Carol. 2006. Multiple voices: An introduction to bilingualism. Malden: Blackwell.

Nygård, Mari and Tor Anders Åfarli. 2015. On the Structure of Gender Assignment. Indian Linguistics 76: 67-76.

Page, B. Richard and Michael T. Putnam (Eds.). 2015. Moribund Germanic Heritage Languages in North America. Theoretical Perspectives and Empirical Findings. Leiden: Brill.

Picallo, M. Carme. 1991. Nominals and Nominalizations in Catalan. Probus 3: 279-316.

Picallo, M. Carme. 2008. Gender and Number in Romance. Lingue e Linguaggio VII: 47-66.

Poplack, Shana. 1980. Sometimes I'll start a conversation in Spanish Y TERMINO EN ESPAÑOL: toward a typology of code switching. Linguistics 18: 581-616.

Poplack, Shana. 1981. Syntactic structure and social function of code-switching. In Latino Language and Communicative Behavior, ed. Richard P. Duran, 169-184. New Jersey: Ablex Publishing Corporation..

Poplack, Shana. 2012. What does the Nonce Borrowing Hypothesis hypothesize? Bilingualism: Language and Cognition 15 (3): 644-648.

Poplack, Shana. 2015. Code-switching: Linguistic. International Encyclopedia of the Social and Behavioral Sciences, 2nd edition, 918-925. Amsterdam: Elsevier Science.

Poplack, Shana and Nathalie Dion. 2012. Myths and facts about loanword development. Language Variation and Change 24: 279-315.

Poplack, Shana, David Sankoff and Chris Miller. 1988. The social correlates and linguistic processes of lexical borrowing and assimilation. Linguistics 26 (1): 47-104.

Ramchand, Gillian. 2008. Verb Meaning and the Lexicon: A First Phase Syntax. Cambridge: Cambridge University Press.

Riksem, Brita R. In press. Language Mixing in American Norwegian Noun Phrases. Journal of Language Contact.

Riksem, Brita R., Maren Berg Grimstad, Tor Anders Åfarli and Terje Lohndal. 2014. The inadequacy of feature-based lexicalist theories: A case-study of American Norwegian. Paper presented at The Fifth Annual Workshop on Immigrant Languages in the Americas, UCLA, Los Angeles, October 17-19.

Ritter, Elizabeth. 1993. Where's Gender? Linguistic Inquiry 24: 795-803. 
Rothman, Jason. 2009. Understanding the nature and outcomes of early bilingualism: Romance languages as heritage languages. International Journal of Bilingualism 13: 155-163.

Sankoff, David and Shana Poplack. 1981. A formal grammar for code-switching. Research on Language and Social Interaction 14: 3-45.

Thomason, Sarah G. 2001. Language contact: An introduction. Edinburgh: Edinburg University Press.

Thomason, Sarah G. 2003. Contact as a source of language change. In A Handbook of Historical Linguistics, eds. Robert D. Janda and Brian D. Joseph, 687-712. Oxford: Blackwell.

Treffers-Daller, Jeanine. 2005. Evidence for insertional codemixing: Mixed compounds and French nominal groups in Brussels Dutch. International Journal of Bilingualism: 9: 477-508.

Winford, Donald. 2003. An introduction to contact linguistics. Malden: Blackwell. 